\title{
DIFFUSION OF APPLICATION SERVICE PROVISION AMONG SMES
}

Who are the adopters?

\author{
Björn Johansson \\ Informatics, Jönköping International Business School, Jönköping University, Sweden
}

\begin{abstract}
This paper provides an exploratory empirical survey of the diffusion of Application Service Providers (ASPs). It does do so by presenting a web survey among small and medium-sized enterprises (SMEs). In addition to that it presents a study on one specific ASP and its clients. The research questions are: how is the ASP concept diffused among SMEs and who are the users among SMEs? The concept, ASP, includes software vendors and an ASP enterprise which acts as a third-party firm in a business model. For its clients the concept forms a strategy to rent applications and organise maintenance of their Information and Communication Technology (ICT). The web survey shows that some knowledge of the ASP concept is widely spread among SMEs. However, a closer examination shows that the knowledge of what the ASP concept actually means is limited. This is seen as one reason why the ASP concept has not taken off among SMEs. This reason is related to the question about trust; in order to trust an innovation there is a need to be knowledgeable about the innovation. The conclusion is that ASPs need to be more explicit about their offer. They also need to show how adoption of the ASP concept affects the adopting organisation.
\end{abstract}

Key words: Adoption, Diffusion, Application Service Provision, SMEs.

\section{INTRODUCTION}

The use of Application Service Providers (ASPs) as providers of Information and Communication Technology (ICT) has been expected to grow significantly. ASPs are often seen as a way for small and mediumsized enterprises (SMEs) to use ICT to increase their effectiveness and efficiency. The ASP concept can be seen as selective ICT outsourcing. The 
outsourcing market is vibrant and receives a great deal of attention. Outsourcing is not a new phenomenon. As early as the mid 1960s there were computer service bureaus which ran a variety of systems for external clients (McFarlan \& Nolan, 1995). These systems were mainly financial and operational applications. And ever since Kodak decided to rent its ICT resources from an external partner in 1989, there has been a trend towards ICT outsourcing (Hirschheim \& Lacity, 2000). Many large companies have decided to transfer their ICT assets, leases, and staff to a third party (Lacity \& Hirschheim, 1993). The degree of ICT outsourcing varies considerably. Some companies outsource just a few ICT functions while others outsource their entire ICT operations (McLellan et al., 1998). In recent years we have seen in the outsourcing market a growing number of ASP start-ups and companies offering their products and services through the ASP concept.

At the same time ASPs struggle with the fact that their inflow of new customers is low. Most reports about the ASP concept are predictions about the growth of the market for ASPs. Kern et al. (2001), for instance, mention that there were over 1,000 companies that claimed to be ASPs during the second quarter of 2001. This can be compared with Lacity \& Willcocks (2001) who say that only 200 firms fitted the ASP definition by mid-2000. Lacity \& Willcocks (2001) predict that the ASP market will rise from US\$ 150 million in 1999 to between US\$ 11.3 billion and US\$ 21 billion by 2003. Firms such as Gartner Group, IDC and Ovum forecast potential market sizes of up to US\$132 billion by 2006 (Kern et al., 2001).

Although the ASP concept is often seen as an exhausted trend, it is commonly considered here to stay. But the frequently asked question is whether customers have a demand for ASPs. My impression is that there is a lack of customers. Gartner Group in 2000 (Kern et al., 2001) predicted that 60 per cent of the ASPs will be out of business. Jayatilaka et al. (2003) state that with the rise in the availability of scalable network technologies the ASP concept will become a more feasible source when it comes to the provision of ICT. They claim that the slow growth is due to the fact that business managers have misunderstood the ASP concept. It can be said to be more fragmented, more complex and riskier than they first thought. The actual adoption rate of the ASP concept is low; according to the ASP Industry Consortium only 8 per cent of firms worldwide use an ASP for the provision of ICT (Jayatilaka et al., 2003).

The core of the ASP concept is for the ASPs to offer applications to external customers. The applications can be IT-related, but such applications are not the only thing that ASPs can offer. An ASP enterprise can, for example, also be some kind of information broker. Puelz (2001) describes an ASP enterprise that benchmarks data from 16 financial institutions. However, the most common way to describe ASPs is as providers that offer 
software applications, which they manage and deliver to external clients (e.g., Cherry Tree, 2001; Kern et al., 2001; Currie \& Seltsikas, 2000). The clients use the application in their own businesses, where the software applications are in areas such as website hosting, payroll/billing, e-mail, ecommerce and ERP applications.

Kern et al. (2002a) describe the difference between an ASP option and other ICT-sourcing options. They mention four general ICT-sourcing models: insourcing, buy-in, traditional outsourcing and the ASP option. The difference between an ASP option and the other ICT-sourcing models is that the resource ownership is on the supplier side in the ASP option. This option is also a one-to-many supplier-customer relationship. Kern et al. (2002b) select the term netsourcing as the overarching name, because the common element in the ASP option is the delivery of a product or service over a network. The primary product of an ASP enterprise is remotely managed business applications. This means that the ASP concept can be seen as an innovation and defined in the following way: an ASP is a third-party firm that supplies, manages and remotely hosts software applications through centrally located data centres on a pay-as-you-use basis. For the client the ASP business model is a strategy to rent software applications and organise its ICT maintenance.

Having defined ASPs and the ASP concept, the remaining question is: how is the ASP concept diffused among SMEs?

The paper presents and discusses findings from two studies, one study on diffusion of the ASP concept among SMEs, and one study investigating who the clients are and for what applications they use an ASP. The paper also specifies reasons given by ASPs why SMEs adopt or ignore the ASP concept. The findings are compared with reasons addressed in the literature. The reasons are used to discuss the diffusion of the ASP concept among SMEs.

The paper first discusses reasons given by SMEs to adopt or discard services from ASPs as reported in the literature. Section three presents a survey among SMEs in Sweden. Section four presents a study of a specific ASP and its clients. The final section summarises and discusses the results.

\section{REASONS FOR ADOPTING OR NOT ADOPTING THE ASP CONCEPT IN SMES}

Kern et al. (2001) point out three reasons why SMEs should adopt the ASP concept. First, even though a package software licence is cheaper than an in-house developed solution, it is still the case that many SMEs cannot afford the packaged solution costs. Second, an SME will be unable to attract 
and afford the necessary ICT staff. Third, the packaged applications require an established ICT infrastructure and connectivity to ensure optimal performance. For an SME it is difficult to retrieve the necessary human and financial resources to support and continually develop such ICT infrastructures. The ASP concept can also be seen as a way for SMEs to take advantage of the rapidly changing opportunities in ICT (e.g. Turban et al., 2001; Currie \& Seltsikas, 2000; Currie \& Seltsikas, 2001). An ASP enterprise can assist SMEs with ICT skills, especially in the development and software maintenance areas (Kern et al., 2001). Dewire (2001) argues that there are eight different reasons for an organisation to adopt the ASP concept. The reasons are: if there is a need for flexible ICT infrastructure, if the organisation cannot afford a huge ICT capital outlay, if it does not have the necessary capital resources, if it needs to scale its ICT infrastructure quickly, if it needs to switch to another environment in the near future, if it needs to deploy applications rapidly, if the organisation finds it difficult to attract and retain ICT staff, and finally if ICT is not a core competency.

The close connection between ICT outsourcing and the ASP concept makes it possible to increase the knowledge of reasons for adopting the ASP concept by comparing them with reasons for ICT outsourcing. One commonly quoted reason for ICT outsourcing is the provision of increased flexibility to cope with changes in technology and in the business environment. Paradoxically, the traditional ICT outsourcing agreement is based on long-term contracts that rather tend to inhibit than facilitate change (Shepherd, 1999). One of the ideas of the ASP concept is to make it possible to have a short-term agreement. According to Lee (2001), outsourcing is motivated by strategic, economic and technological benefits. Shepherd (1999) argues that for the majority of organisations the motives for ICT outsourcing could be summarised as a combination of financial restructuring, reducing or stabilising costs, overcoming cultural and organisational problems, concentrating on core competencies and accessing world-class expertise.

McLellan et al. (1998) give five reasons for ICT outsourcing: financial motivations, the internal IT department does not respond to organisational needs, strategic motivations, to improve long-term business performance and to facilitate strategic change. Whether an organisation should outsource its ICT or not is, according to Weill \& Broadbent (1998), principally a question of what strategy the organisation has.

According to Loof (1995) external suppliers of ICT-sourcing predict large cost reduction, improvements in quality and higher responsiveness if customers hand over their ICT functions to them. He also states that reports on outsourcing are often overly optimistic. The result is that many organisations are in doubt whether there are any benefits for them in 
outsourcing. Udo (2000) says that there is a trend among organisations today to classify ICT functions into two categories according to the kind of services they deliver, commodity services and strategic services. He (2000) maintains that commodity services can be outsourced without having doubts, but strategic services should never be outsourced. However, Udo refers to Lacity \& Hirscheim (1993) who mention that this categorisation can lead to serious problems for an organisation. The reason is that commodity services at present time can be of high strategic importance for the organisation in the future.

According to Udo (2000) providers purpose the following benefits:

- A predictable ICT budget is gained by tying it to actual requirements.

- Lower costs for ICT, which means cost savings compared with both current and future expenditures on ICT equipment.

- Increased access to technological resources and technologically skilled personnel.

- The organisation can focus on core products and services.

- The organisation's fixed costs for ICT can be changed into variable costs.

- The risks in the development of ICT applications are spread.

But, as stated above, Udo (2000) also claims that outsourcing has more disadvantages than advantages. The following potential disadvantages are reported:

- A lack of chemistry between the partners.

- Dependency on another party for the organisation's critical information.

- Loss of ICT capability.

- Loss of control of ICT assets.

- Threat of opportunism from the supplier.

- Loss of flexibility.

- Loss of competitive advantage in information management.

- Loss of ICT expertise and as such loss of memory in the organisation.

- A decline in morale and performance of the remaining employees.

- No guarantee for long-term cost savings.

Baldwin et al. (2001) argue that a selective sourcing approach with the opportunity to use several different suppliers is an increasingly popular strategy to minimise risks, maximise benefits and reduce costs. Jurison (1995) states that there are primarily economic reasons, i.e. economic consideration in different forms is the primary driver for an ICT-outsourcing decision. He mentions risks as the primary reason for not choosing an ICToutsourcing option, where the irreversibility of the decision is seen as the dominant risk. 


\section{A SURVEY OF THE DIFFUSION OF ASP AMONG SMES}

The question in this paper is how the ASP concept is diffused among SMEs. In order to answer that question, results from two different studies are used. This section presents one of them. It was conducted by Isaksson \& Linderoth and is presented in their master thesis (Isaksson \& Linderoth, 2003). The questionnaire was submitted as a web survey to 400 SMEs in Sweden, and data were collected in a database. SME was defined to be an organisation with 10 to 250 employees and an annual turnover not exceeding EUR 40 million (EU Office in Blekinge, 1999). The base for this population was searched out from a list of joint-stock companies. There were 27838 companies that fitted the description of an SME. From the total number of SMEs the survey was submitted to every $70^{\text {th }}$ SME on that list. The total number of responding SMEs was 119. This means that response rate was 30 per cent. However, there were in a follow-up 17 organisations that did not fit the definition of an SME. These respondents' answers were excluded from the study.

The questionnaire consisted of fifteen questions, grouped into three categories. These categories were characteristics of the respondent, grade of diffusion of the ASP concept, and attitudes to the ASP concept. In this paper questions connected with the grade of diffusion of the ASP concept among SMEs are discussed. In the questionnaire there were four questions dealing with this. These questions are presented and the result from them is delivered in sections 3.1 to 3.4 .

\subsection{First question: When did you hear about the ASP concept?}

The first question asked was: when did you first hear about the ASP concept? This question asks two things; first, if the SMEs have heard about the concept as such and second, when they were made aware about it. The respondents could choose from the options shown in Table 1, which also shows the distribution of the answers.

Table 1. Answers to the first question: When did you first hear about the ASP concept?

\begin{tabular}{llc}
$\begin{array}{l}\text { When did you first hear about the ASP } \\
\text { concept? }\end{array}$ & $\begin{array}{l}\text { Distribution of } \\
\text { respondents' answers }\end{array}$ & $\begin{array}{c}\text { Per cent of SMEs } \\
\text { participating in the } \\
\text { questionaire }\end{array}$ \\
\hline Before 1998 & 14 & 14 per cent \\
$1998-2000$ & 43 & 42 percent \\
$2001-2003$ & 32 & 32 per cent \\
Have not heard about the ASP concept & 12 & 12 percent \\
\hline
\end{tabular}


The findings in the table are interesting when compared with, for instance, Jayatilaka et al. (2003) who claim that the ASP concept is a new concept, and most reports on ASP state that the concept was created at the end of the 1990s. According to Kern et al. (2001) this kind of service provision evolved in the late 1990s. IDC, an American analyst company, claims that the idea originated from them in 1998, while the company TeleComputing declares that they coined the expression (Elerud et al., 2001). Despite this 14 per cent say that they heard about the concept before 1998. Irrespective of who coined the term, ever since the late 1990s there has been an increasing interest both among practitioners and researchers in the phenomenon. However, Jayatilaka et al. (2003) say that the concept as such dates back to the 1960s, but then labelled as application hosting. When summing up the numbers in Table 1,88 per cent said they have heard about the ASP concept. From answers to questions later in the study by some of these respondents it appears that they might have heard about the concept but not really understood what ASP in this context is about. One statement was for instance that ASP is an easy programming language, which indicates that the respondent thought it was about active server pages code. The conclusion that can be made from these numbers is that a majority of SMEs have heard about the ASP concept. Only 12 per cent of the respondent said that they had never heard about it.

\subsection{Second question: When did you start to use ASP?}

The second question asked the ones that had heard about the ASP concept: When did you start to use ASP? The answers to this question are shown in Table 2. Also this question was a multiple-choice question, and the possible options to choose among are shown in the table.

Table 2. Answers to the question: When did you start to use ASP?

\begin{tabular}{lll}
\hline $\begin{array}{l}\text { When did you start to use } \\
\text { ASP? }\end{array}$ & $\begin{array}{l}\text { Distribution of } \\
\text { respondents' answers }\end{array}$ & $\begin{array}{l}\text { Per cent of SMEs participating } \\
\text { in the questionaire }\end{array}$ \\
\hline Before 2000 & 5 & 6 per cent \\
During 2000 & 6 & 7 per cent \\
During 2001 & 3 & 3 per cent \\
After 2001 & 8 & 9 per cent \\
Do not use ASP & 67 & 75 per cent \\
\hline
\end{tabular}

The numbers show that among the SMEs that had heard about ASP most do not use ASP. The SMEs that use ASP are distributed fairly equally over time. However, there is a drop during 2001, which is amazing since during this time heavy marketing was done about the ASP concept. An explanation of the drop in 2001 can be that ASPs had a very negative performance on the stock market during that time (Cherry Tree \& Co, 2001). This had an impact 
on clients' purchasing patterns. The numbers reveal that 79 per cent do not use the ASP concept and 21 per cent uses the ASP concept. The question is to what degree they use ASP. This will be discussed in the next section.

\subsection{Third question: To what degree is the ASP concept used?}

The third question asked was: To what degree is your organisation's ICT provided through the ASP concept? This question was answered by the organisations who in the answer to the second question stated that they used the ASP concept. The statements and the answers are shown in Table 3.

Table 3. Answers to the question: To what degree is your organisation using the ASP concept?

\begin{tabular}{lll}
\hline $\begin{array}{l}\text { To what degree is your } \\
\text { organisation's ICT provided } \\
\text { through the ASP concept? }\end{array}$ & $\begin{array}{l}\text { Distribution of respondents' } \\
\text { answers }\end{array}$ & $\begin{array}{l}\text { Per cent of SMEs } \\
\text { participating in the } \\
\text { questionnaire }\end{array}$ \\
\hline $\begin{array}{l}\text { Less than } 20 \text { per cent } \\
20-40 \text { per cent }\end{array}$ & 14 & 65 per cent \\
$40-60$ per cent & 0 & 27 per cent \\
$60-80$ per cent & 1 & 4 per cent \\
$80-100$ per cent & 1 & 4 per cent \\
\hline
\end{tabular}

The answers show that 65 per cent of the SMEs use the ASP concept for less than 20 per cent of their ICT. This means that in this case the ASP concept can be compared to selective outsourcing. According to Willcocks (1994) selective outsourcing is when an organisation outsources less than 80 per cent of their ICT budget. Selective outsourcing consequently means a mix of outsourcing and internally managed ICT. The findings also show that only four per cent use the ASP concept for the provision of their ICT to a degree of 80 per cent. This implies that ASP in this case can not be seen as total outsorcing. Total outsourcing is defined by Willcocks (1994) as when at least 80 per cent of an organisation's ICT budget is spent on external partners. The results build on a fairly small number of SMEs. However, they give some indication of how the ASP concept is used. Another indication is obtained by looking at what applications the SMEs buy as an ASP service. That is the question presented in the next section.

\subsection{Fourth question: What applications are provided through the ASP concept?}

The fourth and final question presented from the survey among SMEs is a question that deals with what kind of applications are provided through the ASP concept. The SMEs that answered this question were those who stated 
they were using ASP. There were ten different systems or categories of systems that the respondents had to choose among. There was also a possibility to describe other kinds of systems they rented from an ASP. The most used systems among the ASP customers are financial systems and tools for publishing on the web. These two categories of systems were used by 37 per cent of the SMEs that used an ASP for the provision of ICT. An interesting finding is that office suites were provided as an ASP service to 16 per cent of the ASP customers. This is interesting because when discussing with ASPs on what applications they deliver, an office suite is seen as the basic offer that all customers need and also have.

To deepen the findings from the web survey they are compared with findings from the second study, which is presented below. The second study was conducted among customers to a specific ASP and part of an exploratory study of the ASP concept.

\section{A STUDY OF AN ASP AND ITS CUSTOMERS}

The second study was directed to customers of a specific ASP, acting as a horizontal ASP. According to Currie \& Seltsikas (2000) an ASP is categorised as a horizontal ASP if it offers collaboration tools and other applications to a broad base of customers'. The focus is mainly on business processes. The ASP studied fits this description insofar as it does not focus on a specific industry. Instead it tries to support its customers with all ICT applications they need. The first part of the study of the horizontal ASP, which is presented in Section 4.1, can be described as an exploratory study. It was conducted as open-ended, semi-structured interviews with the service provider. Two interviews with sales managers at the service provider were done (November 2001 and February 2003). The interviews were taperecorded and transcribed. There were two overall questions in the interview with the ASP: 1) what do they deliver? and 2) why should SMEs adopt the ASP concept?

\subsection{The ASP company}

When the first interview was conducted the ASP was a consulting firm located in Denmark, Norway and Sweden. The company was the result of mergers of three different companies; the three companies were an Internet Service Provider (ISP), an IT-consultant, and an ASP-firm. The history of the organisation can be seen as an expression of the still ongoing consolidation among service provider organisations. The organisation conducted its business under one name for almost a year before it went 
bankrupt. Almost directly it was restarted as a new firm. According to the interviewee in November 2001the company was a leading ASP actor in Scandinavia with a steady inflow of new customers. The organisation's data centre in combination with ISP service and IT-consultancy experiences makes the company well prepared to become a competitive player in the ASP market. Currently (November 2003) the organisation has 45 employees located at five places. According to the interviewee the background of the ASP offers a possibility for the company to provide their customers with flexible solutions.

\subsubsection{Applications and services provided by the ASP}

There are two different types of services provided - a consultancy and a hosting part. The type examined here is the hosting part. It is described as an offer of a flexible solution to customers. This flexible solution consists of a base block and a block of customer-specified solutions. The base block consists of Microsoft's Outlook, Explorer, Office, Project, and WinZip. The base block is needed for the service provider to increase its volumes and to make a profit. The second part is customer-specific applications that customers either already have or want to have. These solutions can, for example, comprise payroll/billing, e-commerce and ERP applications. The ASP portfolio of the ASP studied includes between 80 and 90 different software applications.

There are two ways of implementing the applications, dedicated servers or one-to-many servers. Currently the firm focuses on finding applications aimed at being suitable for the one-to-many solution. According to the interviewees the ASP concept has had some problems. One of the problems was that too much was promised in the first stage. It was stated that the ASP concept should be able to take care of all ICT including all services and support for their clients. This has not been possible to fulfil due to the fact that it is not possible to handle all applications as an externally hosted application. The ASP has tackled this situation by taking a complete view of their customers and now it develops and manages some applications at their customers' places as well. The aim is to move these customer applications to the data centre of the ASP. The aim of the ASP is to be a provider of all necessary ICT and ICT services for their customers.

\subsubsection{Why become a customer?}

The ASP company's customer segment is small and medium-sized enterprises (SMEs), where the ordinary customer has an e-mail system and an office packet as its basic ICT. In addition, a customer often rents a 
customer relationship (CRM), an accounting and/or an enterprise resource planning (ERP) system. The main reasons for adopting the ASP concept are, as stated by the interviewees in the ASP:

- A customer does not want to have extensive ICT-competence.

- Getting 24/7 accessibility to applications-according to the interviewees, SMEs have problems with providing this amount of accessibility.

- Access to a helpdesk function.

- To get control of their ICT-costs, customers want to know the ICT cost per user every month.

- To get full control of ICT investments.

- To increase their ICT security — help in tackling spam and virus problems as well as internal security issues, for example, backups.

- To get rid of problems with software upgrades.

Two main reasons for not adopting the ASP concept emerged from the interviews:

- Losing control of data by having data at the ASP's data centre.

- Cost - many presumptive customers say that, based on a calculation from the ASP, ICT and associated services will cost too much.

Both these reasons for not adopting the ASP concept are handled by the ASP. The fear of losing control is addressed by showing how the concept works. The ASP uses a specific model showing how the customer is "implemented" in the data centre and the customer can see how security is handled and how the company's system is protected against intruders. The cost reason is addressed by doing a total cost of ownership (TCO) analysis. If the customer permits the ASP to do this TCO analysis it will get a good picture of its current ICT costs and these costs can be compared with the ASP fee.

\subsection{The survey of the ASP customers}

The second part in the study was a survey of the ASP's customers. The questionnaire used consisted of twenty-one questions. This report focuses on three questions: two related to who the customer is and one related to what applications are rented from the ASP. The questionnaire was sent to all customers identified as ASP customers. In this study, an ASP customer is defined as an organisation using at least one rented software application in its organisation. Using the definition, there were 17 ASP customers identified. Fourteen of these customers responded to the questionnaire. In developing the questionnaire results from the interviews as well as from two other studies were used. Currie \& Seltsikas (2000) developed a framework for evaluating ASP offers. The framework consists of four different categories and related performance criteria. Susarla et al (2003) did an 
empirical analysis of ASP satisfaction. The study focused on four different areas: 1) satisfaction in terms of organisational attitudes, 2) expectations about the service, 3) perceived disconfirmation and 4) perceived provider performance. The questions used in this study focus on who the customers are and what applications are provided from the ASP.

\subsubsection{Who are the customers of the ASP?}

The questionnaire started with questions about who the customers are and some characteristics of the customers. The first question asked was: Which option describes your organisation best? The answer is shown in Figure 1.

A majority of the customers describe themselves as service organisations. However, to deepen this description, the second question asked was: Which option describes your customers best? The answer is shown in Figure 2. A majority of the ASP customers identified their customers as other organisations. 77 per cent said that the option "mainly other companies" described their customers best.

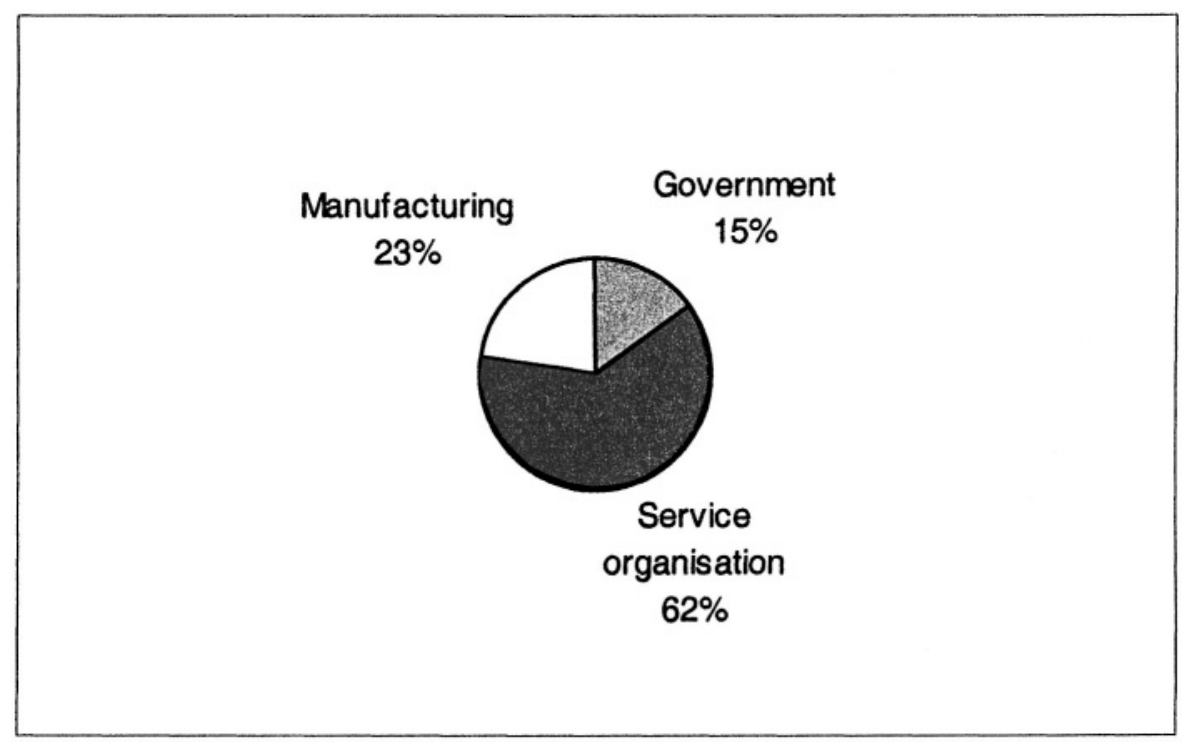

Figure 1. Answer to the question: Which option describes your organisation best?

The answers to these two questions show what kind of customers the horizontal ASP has. Analysing the two questions together leads to interesting conclusions. One conclusion is that a large number of the customer states that they are service organisations that have other companies 
as their customers. This implies that the ASP customers are used to cooperating with other companies. Another possible conclusion is that the ASP concept is more used among organisations that provide their customers with information. This is in contradiction to a reason that is often put forward for adopting the ASP concept - to focus on core competence. In the study only 23 per cent of the organisations identified themselves as a manufacturing industry, and for those organisations ICT could certainly be said not to be their core competence.

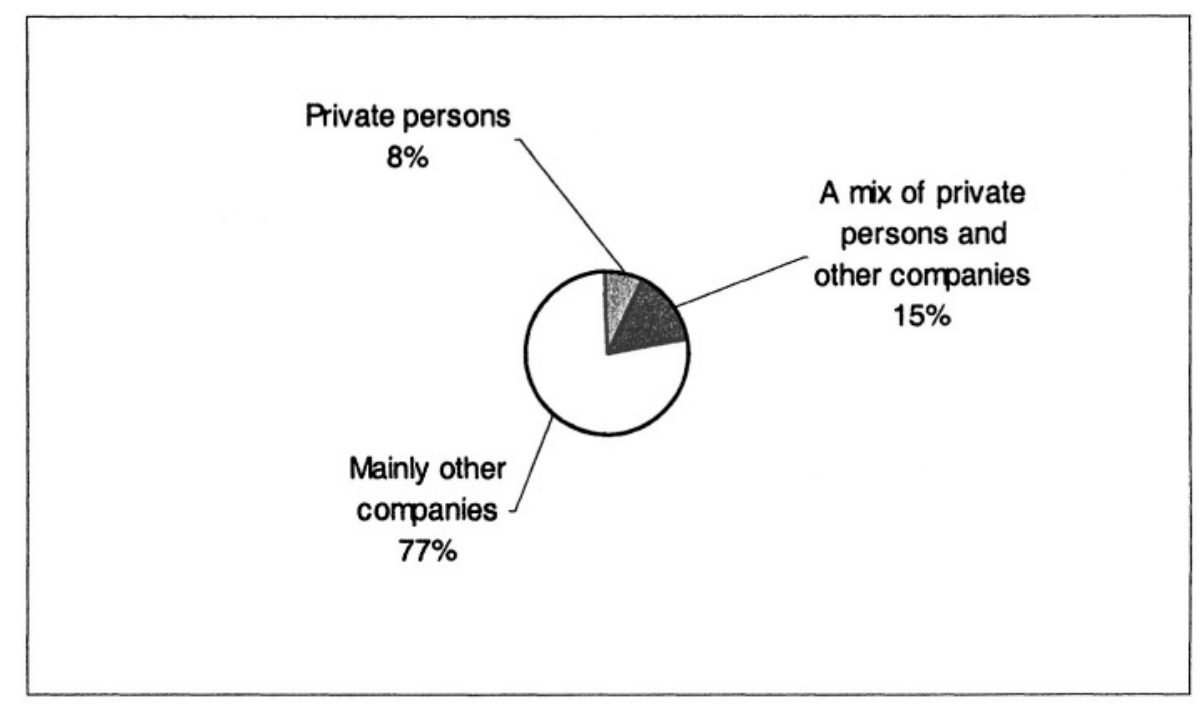

Figure 2. Answer to the question: Which option describes your organisation's customer best.

A statement often made concerning who the ASP concept fits, is that the ASP concept demands a network connection and if the organisation does not already have this the ASP concept is not suitable. That ASP demands a network connection is so self-evident that it does not have to be questioned. However, the statement from the interviewees at the service provider organisation declares that it only fits organisations that are located at different places. This statement was tested by asking the customers of the horizontal ASP if they are located in more than one place.

The result shows that 62 per cent of the organisations are located in more than one place. However, the rest of the customers are located at only one place which contradicts the statement made by the service provider. In order to explain this finding it is fruitful to look at who the users are and what function they have in the organisation. 


\subsubsection{Who uses the applications provided by the ASP?}

The survey established which categories of employees use applications provided by the service provider. The result is shown in Table 4 .

Table 4. Categories of employees using applications provided by the ASP.

\begin{tabular}{llll}
\hline $\begin{array}{l}\text { Category of } \\
\text { employees }\end{array}$ & $\begin{array}{l}\text { Number of } \\
\text { organisations with } \\
\text { users in the } \\
\text { respective category } \\
\text { (total number of } \\
\text { organisations) }\end{array}$ & $\begin{array}{l}\text { Per cent of } \\
\text { organisations that } \\
\text { use rented } \\
\text { applications in the } \\
\text { respective category }\end{array}$ & $\begin{array}{l}\text { Per cent of } \\
\text { organisations that } \\
\text { do not use rented } \\
\text { applications in the } \\
\text { respective category }\end{array}$ \\
\hline $\begin{array}{l}\text { Administrator } \\
\text { Service staff }\end{array}$ & $12(13)$ & 92 per cent & 8 per cent \\
Factory hand & $2(8)$ & $\begin{array}{l}75 \text { per cent } \\
\text { 67 per cent }\end{array}$ & $\begin{array}{l}\text { 25 per cent } \\
\text { Other employees }\end{array}$ \\
\hline
\end{tabular}

One finding is that 46 per cent of the organisations have "other employees" that use applications from the service provider. The majority of employees in this group are salesmen and consultants. Five organisations out of six describe "other employees" as salesmen and consultants. These employees need to have access to the organisation's system when they are outside the organisation's premises. This can maybe explain the finding that 38 per cent of the customers are only located at one geographical place. The service providers claim that there are two basic characteristics of the SMEs, at least one of which has to be fulfilled if the ASP concept should be interesting for SMEs. One characteristic is that the SMEs should be located at several places. The other characteristic is that they have employees that need to have access to applications from various locations. The first interpretation of why organisations located at one single place have adopted the ASP concept is that they probably have sales personnel that need to have access to the organisation's applications from various places. However, this statement is not supported when the data are examined in detail. Instead customer organisations that have sales personnel are also located at several places. Four out of the eight customer organisations located at several places state that they have sales staff. Only one customer organisation is located at one place and has sales staff. The possibility to have access from anywhere is something that service providers emphasise as one benefit of the ASP concept. If an organisation decides on using the ASP concept the organisation also obtains increased accessibility. The only thing needed according to the service providers is a connection to the Internet. 


\subsubsection{What applications are rented from the ASP?}

To get an understanding of what applications are rented from the ASP the study investigated what applications the customers rent, what applications they do not rent and what applications they do not use. The study included twelve different categories of software applications. The result is shown in Table 5.

Table 5. Applications in the ASP customer organisations.

\begin{tabular}{llll}
\hline Software application & Rented & Not rented & Not used \\
\hline Office suites (e.g. MS Office) & 11 & 2 & \\
e-mail systems & 11 & 2 & 4 \\
ERP systems & 9 & & \\
Website & 9 & 1 & 1 \\
Finance systems & 9 & 3 & 3 \\
Accounting systems & 8 & 2 & 2 \\
Payroll systems & 6 & 4 & 8 \\
MPS systems & 4 & & 8 \\
CRM systems & 3 & 1 & 8 \\
CAD/CAM systems & 2 & 2 & 8 \\
e-commerce & 1 & 1 & 9 \\
Video conferencing systems & 1 & & \\
Other systems & 3 & & \\
\hline
\end{tabular}

Table 5 shows how many organisations use and rent, use but do not rent respectively do not use categorised software applications. The sum of each row in the table should be thirteen. However, some of the respondents did not give answers in all categories. In all likelihood respondents who did not mention some applications do not use those applications in the organisation. The result shows that the most commonly used and rented applications are office suites (MS Office) and e-mail systems. These are software applications that are very common in organisations today. These two applications are also seen by ASPs as the basic option and it is more or less compulsory to rent them.

Two of the organisations have chosen not to rent an office suite, despite the fact that they use one. One of the organisations only rents an ERP system including accounting and payroll. The other organisation has its website located at the service provider and rents a payroll and an accounting system from the service provider. It can be concluded from this that they do not really utilise all the advantages the ASP concept can offer, for instance the advantages of easily upgraded versions. One explanation for why the two organisations do not rent the office suite can be that they already have paid for the licence and do not see any reason for transferring these systems to an ASP. This explanation is supported in the interviews when the ASPs claim 
that one of the difficulties in the ASP concept is how to handle the licence fee.

More advanced applications such as customer relationship management (CRM) and e-commerce are not so widely used among the customers. One reason for this is perhaps the fact that these applications have not yet been discovered by SMEs or maybe they were discovered but are not needed in SMEs. Another explanation is that SMEs first rent basic applications and when they have more experience from the provider and the concept as such they expand their use of ASP. This latest explanation is supported by the ASPs, who claim that often a customer starts by renting, for instance, Microsoft Office and later on, when they are familiar with the concept and the service provider is familiar with the customer, more customer-adjusted applications are rented. If this is the case there should be a correlation between when the customer adopted the ASP concept and what applications they use. When searching the data for this correlation it was found that among organisations that use software applications that are not rented nonrented applications were equally distributed among the customers.

\section{CONCLUSIONS}

The paper describes what the ASP concept is used for and who the ASP customers are. It can be concluded that the ASP concept and the services delivered from an ASP do not focus on a specific customer segment. The basic idea of the ASP concept and the business model of the investigated ASP to aim at being a complete provider of software applications, has not been found to be fulfilled. Instead the usage is more in line with selective outsourcing as described by Baldwin et al. (2001). The web-based survey of SMEs found that financial systems and tools for publishing on the web were the most rented applications. This was not supported in the findings from the study of ASP customers of the horizontal ASP. The most common applications rented from this service provider are office suites (MS Office) and e-mail systems.

There are several reported reasons why an SME should adopt the ASP concept. At the same time it can be stated that SMEs know what ASP is about. However, it can also be stated that the knowledge and deep understanding of what ASP exactly means is inadequate. This could be seen as one reason why the diffusion and adoption of the ASP concept is reported as limited.

If the reported benefits are true, why do SMEs not adopt the ASP concept? One explanation is that the reported benefits can be seen as 
strategic. By strategic is meant that the benefits are seen as a way of improving the organisation over a longer period.

The reported risks on the other hand can be seen as more direct and affect the organisation in a more direct manner. Does this have anything to do with the diffusion of the ASP concept among SMEs? It can be concluded that it has if the SMEs are seen as more operational in their decision-making. It can be stated that managers in SMEs need to solve their organisation's problems at once and do not have enough time or energy to always make strategic decisions. This implies that the risks have a stronger impact on the decision to adopt or not. The SMEs need to solve the problems at hand and if an adoption of the ASP concept does not solve the existing problems, they will probably not even think of adopting something that could imply new problems even if it would solve the problems in a longer term perspective.

The service provider states that the ASP concept is suitable only if the SMEs are located at several places and have a network communication already. The reason they give for this statement is that otherwise it will be too costly to implement and use ASP for SMEs. In this study it was not found to be the case. Instead 38 per cent of the customers have decided on using the ASP for the provision of their ICT, despite the fact that they are only located at one place. The reason for this could be that these customers have employees that need to have access to their applications at a distance. The need of having access to applications on a distance is another statement the provider gives for what organisation the ASP concept fits. However, this was not supported in the study. It was found that the customer located at one place did not have employees that needed distance access.

When the first interview was conducted in November 2001 the provider stated that only 10 per cent of their customers used the Internet for network communication. Since then this have changed and at the moment (October 2003) the Internet is used by 35 per cent of their customers. One reason why the use of the Internet has increased is probably increased trust in the Internet. Lack of trust is probably one reason why the ASP concept has not taken off. The conclusion that the ASP concept has not taken off can be drawn despite the fact that 88 per cent of the SMEs know about the concept. The limited use of the ASP concept in SMEs has probably several different reasons. One of the most commonly reported reasons is, as stated above, trust, both when it comes to trust in the technology as such and trust in the partner to cooperate with.

According to the service provider one reason for the low uptake of ASP can be that it promised too much in the beginning. This statement can be compared to Hagel's (2002) statement that the ASP concept was introduced too soon. He claims that one reason for the low uptake was that the offer from ASPs was not developed for the ASP business model. Many 
applications were not adapted to network use. The result was that ASPs started to deliver ASP services as a service hosted at the customer's place, which means that the original ASP concept became blurred.

Another reason why the diffusion of ASP has been limited can be an effect of the dotcom collapse and the impact this has had on investments in ICT. If this is the reason one can conjecture that it will change and that we will see an increase in the use of the ASP concept in the future, but this will only happen if the ASPs show profit and if the applications they offer are needed by SMEs. However, it also requires trust in the new ways of providing ICT at a distance over a network.

The main finding in this paper is the fact that SMEs state that they know what ASP is. However, the study shows that the knowledge of the ASP concept among SMEs is limited. When asked, ASP customers gave various interpretations of the ASP concept. This is also indicated in a study by Isaksson \& Linderoth (2003) who claim that 88 per cent of SMEs say they know what ASP is, but at the same time their study shows that there is a lack of knowledge among SMEs about what the ASP concept actually means. However, answering the question whether they were familiar with the ASP concept, all customers said they were, which is not surprising since the question was put to ASP customers. More interesting are the different explanations of what the concept means to them. To some customers the ASP concept means that they just rent storage. To other customers the ASP concept means that the service provider reengineers the organisation's business processes. The most common statement is that the ASP concept means that an external provider takes care of the management of software applications and makes sure they work. It can be concluded from this that the ASP concept from the customers' view is seen as something operational and not something strategic. This conclusion is based on the fact that customers do not describe the ASP concept as a way of improving their business over a longer period. It can also be concluded that the adoption or non-adoption of the ASP concept depends on whether the potential customer has trust in the concept. And in order to have trust there is a need to be knowledgeable. The implication of this is that ASPs need to be clearer about what their offer consists of. They also need to show how the adoption of the ASP concept affects the adopting organisation.

\section{REFERENCES}

Baldwin, LP., Irani, Z., \& Love, PED. (2001). Outsourcing information systems: drawing lessons from a banking case study. European Journal of Information Systems Vol. 10 pp. $15-24$. 
Cherry Tree \& Co. (2001). Trends in Outsourcing: Strong, Sustainable and Growing, Spotlight Report, July.

Currie, W.L. \& Seltsikas, P. (2000). Evaluating the application service provider (ASP) business model, Executive Publication Series CSIS2000/004, Centre for Strategic Information Systems, Department of Information Systems \& Computing, Brunel University, Uxbridge, UK.

Currie, W.L. \& Seltsikas, P. (2001). Exploring the supply-side of IT outsourcing: evaluating the emerging role of application service providers, European Journal of Information Systems, Vol 10, pp 123-134.

Dewire, D. T. (2000). Application service providers, Information Systems Management, Vol 17, No 4, pp 14-19.

Elerud, F., Gustafsson, T., \& Jusufagic, M. (2001). ASP - Framtidens IT-drift? Ett strategiskt perspektiv. Master thesis, Företagsekonomiska Institutionen, Lunds Universitet.

EU Office in Blekinge. (1999). EU-bidrag: korta råd och tips om projektbidrag från EU. http://eu-kontoret.softcenter.se/hursok.htm 2003-03-14.

Hagel, J. (2002). Out of the Box. Harvard Business School Press, Boston, MA.

Hirschheim, R. \& Lacity M. (2000). The myths and realities of information technology insourcing, Communications of the ACM, Vol 43, No 2, pp 99-107.

Isaksson, R., \& Linderoth, P. (2001). Application Service Provision for SMEs: Vision or reality? Master thesis in Informatics, Jönköping International Business School, Jönköping University.

Jayatilaka, B., Schwarz, A., \& Hirschheim, R. (2003). Determinants of ASP choice: an integrated perspective. European Journal of Information Systems, Vol. 12 pp 210 - 224.

Jurison, J. (1995). The role of risk and return in information technology outsourcing decisions. Journal of Information Technology, 10, pp 239-247

Kern, T., Lacity, M., Willcocks. L. (2002b). Netsourcing: Renting Business Applications and Services Over a Network. Financial Times Prentice Hall, Upper Saddle River, New Jersey.

Kern, T., Lacity, M., Willcocks. L., Zuiderwijk, R. \& Teunissen, W. (2001). ASP Market Space Report 2001. Mastering the Customers Expectations, GMG report.

Kern, T., Willcocks, L. \& Lacity, M. (2002a). Application Service Provision: Risk Assessment and Mitigation. MIS Quartely Executive 1 (2) pp 113-126.

Lacity, M. \& Hirschheim, R. (1993). Information Systems Outsourcing: Myths, Metaphors and Reality, John Wiley \& Sons, Chicester.

Lacity, M. \& Willcocks, L. (2001). Global Information Technology Outsourcing: In Search of Business Advantage, John Wiley \& Sons, Chichester.

Lee, J-N. (2001). The impact of knowledge sharing, organizational capability and partnership quality on IS outsourcing success, Information \& Management, Vol 38, pp 323-335.

Looff, L.A. de (1995). Information systems outsourcing decision making: a framework, organizational theories and case studies. Journal of Information Technology, 10, pp 281297.

McFarlan, F.W. \& Nolan, R.L. (1995). How to manage an IT outsourcing alliance, Sloan Management Review, Winter, pp 9-23.

McLellan, K., Marcolin, B.L. \& Baemish, P.W. (1998). Financial and strategic motivations behind IS outsourcing, in Strategic Sourcing of Information Systems, L.P. Willcocks \& M.C. Lacity (Eds), John Wiley \& Sons, Chicester, pp 207-248.

Puelz, R. (2001). Entrepreneurship and an ASP in financial services, Journal of Business \& Entrepreneurship, Vol 13, Special Issue, October, pp 33-55.

Shepherd, A. (1999). Outsourcing IT in a Changing World. European Management Journal, vol.17, no. 1. pp 64-80. 
Susarla, A., Barua, A. \& Whinston, A.B. (2003). "Understanding the service component of application service provision: an empirical analysis of satisfaction with ASP services", MIS Quarterly, Vol 27, No1, pp 91-123.

Turban, E. McLean, E. \& Wetherbe, J. (2001). Information technology for management: Making Connections for Strategic Advantage, second edition. John Wiley \& Sons Ltd, Chicester.

Udo, G.G. (2000). Using analytic hierarchy process to analyze the informationtechnology outsourcing decision. Industrial Management \& Data Systems. MCB University press 100/9 pp. 421 - 429. http://www.emerald-library.com

Weill, P. \& Broadbent, M. (1998). Leveraging the New Infrastructure. Harvard Business School Press, Boston

Willcocks, L. (1994). Collaborating to Compete: Towards Strategic Partnerships In IT Outsourcing. Oxford Institute of Information Management, RDP94/11. Templeton College, Oxford. 